\title{
Effect of acute hyperglycemia on clotting time and relative plasma viscosity (RPV) during menstruation
}

\author{
A. OMOROGIUWA* and O. OKOLO \\ Department of Physiology, School of Basic Medical Sciences, College of Medical Sciences, \\ University of Benin, Benin City, Nigeria. \\ *Corresponding author; E-mail: ask4ade2006@yahoo.com; Tel: +234(0)7039460340
}

\begin{abstract}
Menstruating females seem to bleed more when they ingest sugar or sugar containing substances. This study was carried out to determine the effect of acute hyperglycemia on clotting time and relative plasma viscosity during menstruation. Forty menstruating females from the St. Philomena School of Midwifery, Benin, Nigeria volunteered for the study. following ethical approval from St. Philomena Catholic Hospital, blood samples were collected from the ante cubital vein; pre-ingestion, one hour and two hours post ingestion of glucose concentrations $\quad(39 \mathrm{~g} / 200 \mathrm{ml}, 78 \mathrm{~g} / 200 \mathrm{ml})$. Fasting blood samples and post glucose ingestion blood samples were analyzed for Sugar, Clotting time and Relative Plasma Viscosity (RPV) using Standard laboratory methods. Results were analyzed with paired t-test and values of $\mathrm{p}<0.05$ were considered statistically significant. The result showed a statistically significant increase $(\mathrm{p}<0.05)$ in clotting time and a decrease in relative plasma viscosity $(\mathrm{p}<0.05)$ one hour after the intake of both glucose concentrations. Two hours after glucose intake, there was a decrease in clotting time towards the baseline and an increase in RPV towards the baseline. This study thus suggests that acute hyperglycemia increases clotting time and reduced RPV in menstruating girls. This may be the reason for the perceived sense of increased menstrual flow.
\end{abstract}

(C) 2015 International Formulae Group. All rights reserved.

Keywords: Clotting time, Relative Plasma Viscosity (RPV), menstruation, blood sugar.

\section{INTRODUCTION}

Menstruation results from a complex interaction between the hypothalamus, the anterior pituitary gland, the ovaries and uterus (Guyton and Hall, 2006) and it typically indicates that fertilization did not occur. In the absence of pregnancy, the fall of plasma progesterone concentration due to corpus luteum involution triggers menstrual endometrium remodeling, leading to shedding of its functional layer associated with bleeding (Pauline et al., 2013). This desquamation is linked and controlled by cyclical fluctuations in the levels of follicle stimulating hormone, luteinizing hormone, estrogen and progesterone. However, despite this intrinsic hormonal effect, extrinsic factors such as diet and life style can still influence menstrual flow and cycle. Studies have shown that nonmodifiable host factors such as ethnicity and potentially modifiable risk factors such as smoking, physical activity and alcohol may affect menstrual cycle outcome (Liu et al., 2004). Dieting, a self-induced attempt to restrict food consumption can result to low serum leptin and in extreme cases of dieting 
such as anorexia nervosa there can be disturbance of ovulatory function and abnormal menstrual cycle (Franca et al., 2000). Furthermore, stress and overwhelming fluctuation in weight and has been found to affect menstruation. During stress, the increased secretion of cortisol causes functional menstrual abnormalities (Loucks and Redman, 2004). Functional menstrual abnormalities such as delayed or reduced flow menstrual flow are traceable to the decreased release of estrogen and progesterone occasioned by the increased secretion of cortisol.

Clotting time which is the required for clot formation is one of the tests carried out during blood coagulation test, in addition to bleeding time and thrombin time. Coagulation involves both cellular (platelet) and protein (coagulation factor) component (Furie and Furie 2005) i.e it involves the intrinsic and extrinsic pathway with both occurring simultaneously. Tissue factor initiates the extrinsic pathway whereas the contact of factor XII (Hageman factor) and platelet with collagen in the vascular wall initiates the intrinsic pathway. Clot begins to form about 15-20 seconds later, if the trauma to the vascular wall is severe and 1-2 minutes if it is not severe (Guyton and Hall, 2006). As the bleeding time is correlated with the platelet levels, studies show that during menstrual phase, platelet count decreased and bleeding time increased, whereas around mid-cycle platelet count increased and bleeding time decreased (Rajnee et al., 2010). Earlier studies have shown that increase intake of glucose increases clotting time (Moreno et al., 2000). Plasma viscosity is essentially a measure of plasma protein changes, its level can change in parallel with fibrinogen, especially in acute phase response (e.g., in acute ischemic events), but can also be influenced by the level of triglycerides (Gabor et al., 2008). Relative plasma viscosity is the flow rate of plasma relative to the flow rate of distilled water (Reid and Ugwu, 1987). It has been shown that blood viscosity and plasma viscosity decreases during menstruation and peak at about $7^{\text {th }}$ and 21 st day respectively, but fibrinogen which is the major determinant of plasma viscosity is found to be higher during menstruation (Dapper and Dida., 2002). Increase in blood glucose has been shown to increase relative plasma viscosity in diabetic patients (Olatunji et al., 2008) i.e. diabetes is a procoagulable state. This study is aimed at determining the effect of ingestion of varying concentrations glucose on clotting time and relative plasma viscosity during menstruation, in a view to assessing the impact of sugar on the intensity of bleeding during menstruation.

\section{MATERIALS AND METHODS}

Forty menstruating subjects between the ages of 18 and 25 from the St Philomena School of Mid-wifery in Benin City, Nigeria volunteered for the study. Demographic and menstrual cycle data were obtained by using a semi-structured questionnaire. The inclusion criteria were subjects aged 18 to 25 , second day of menses, regular menstrual cycle while the exclusion criteria were history of anemia, use of contraceptive, history of diabetes and history of coagulation disorder.

By $9.00 \mathrm{am}$, the subjects arrived the laboratory and they were allowed to settle down. Few minutes after, $6 \mathrm{mls}$ of their fasting blood samples were collected from the ante cubital vein using a $21 \mathrm{G}$ bore needle in a 10 $\mathrm{ml}$ syringe. $2 \mathrm{ml}$ of the collected blood sample was then injected into a fluoride oxalate bottle and the other $4 \mathrm{mls}$ into another anticoagulated bottle. Thereafter, twenty of them were given $39 \mathrm{~g}$ glucose $/ 200 \mathrm{mls}$ of water and the other twenty subjects were given $78 \mathrm{~g}$ glucose $/ 200 \mathrm{mls}$ of water. Blood samples were again collected from the ante cubital vein using a $21 \mathrm{G}$ bore needle in a $10 \mathrm{ml}$ syringe at 1 hour and 2 hours following the ingestion of glucose solution. Blood Sugar was analyzed using a colorimeter, Relative Plasma Viscosity (RPV) was assessed by a method described by Reids and Ugwu (1987) and clotting time was assessed using capillary tube method. 


\section{Statistical analysis}

Data were presented as mean \pm standard deviation using the Microsoft excel 2010 analyzed using the student's paired t-test.

\section{Ethics}

Ethical clearance was obtained from the Ethics and Collaboration Committee of the St Philomena Catholic Hospital where the study was done. Informed consent was also obtained from the subjects.

\section{RESULTS}

The mean age, height and weight of the subjects studied were $21.51 \pm 3.97$ years, $1.59 \pm$ $0.11 \mathrm{~m}$ and $59.33 \pm 3.33 \mathrm{~kg}$ respectively. While the age range for menarche and menstrual cycle length were 12-14 years and 28-30 years respectively. 36 (90\%) experienced increased use of sanitary pads following ingestion of sugar solutions, while $4(10 \%)$ observed no change in the number of sanitary pads used. None of the subjects experienced an increase in the number of days of menstruation following ingestion of sugary solutions.

The mean values for blood sugar after the ingestion of $39 \mathrm{~g}$ glucose in $200 \mathrm{ml}$ of water and $78 \mathrm{~g}$ glucose in $200 \mathrm{ml}$ of water were compared to the base line values and the blood sugar was found to be higher $(\mathrm{p}<0.05)$ at the 1 hour post ingestion of glucose solution at both concentrations (Table 1). However, the difference in blood sugar at 2 hours post ingestion of both solutions of glucose when compared to baseline was not statistically significant $(\mathrm{p}>0.05)$.

Table 1: Blood sugar (BS) levels before and after ingestion of $39 \mathrm{~g}$ of glucose $/ 200 \mathrm{mls}$ water and $78 \mathrm{~g}$ of glucose $/ 200 \mathrm{mls}$ water.

\begin{tabular}{lcc}
\hline $\begin{array}{l}\text { BS }(\mathbf{m g} / \mathbf{d l}) \text { before and after } \\
\text { ingestion of } \mathbf{3 9} \mathbf{g} \text { of glucose/200 } \mathbf{~ m l s} \\
\text { water }\end{array}$ & $\begin{array}{c}\text { BS }(\mathbf{m g} / \mathbf{d l}) \text { before and } \\
\text { after ingestion of } \mathbf{7 8} \mathbf{g} \text { of } \\
\text { glucose/200 } \mathbf{~ m l s ~ w a t e r ~}\end{array}$ & Time (Hr) \\
\hline $88.22 \pm 4.26$ & $88.18 \pm 3.14$ & 0 \\
$144.12 \pm 2.13^{*}$ & $161.54 \pm 3.33^{*}$ & 1 \\
$91.23 \pm 2.86$ & $90.47 \pm 2.68$ & 2 \\
\hline
\end{tabular}

Superscripts $\left(^{*}\right)$ depict significant differences between $0 \mathrm{hr}$ or baseline and $1 \mathrm{hr}$ and $2 \mathrm{hrs}$ after $\quad$ ingestion of glucose solutions and analyzed by Paired t- test at $\mathrm{P}<0.05$.

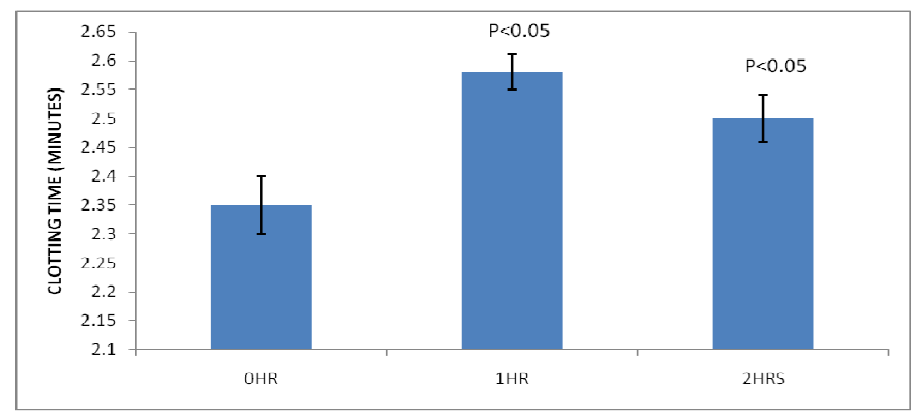

Figure 1: Clotting time at $1 \mathrm{hr}$ and $2 \mathrm{hrs}$ after the ingestion of $39 \mathrm{~g}$ of glucose $/ 200 \mathrm{mls}$. The Clotting time value after one hour of the ingestion of $39 \mathrm{~g}$ glucose $/ 200 \mathrm{mls}$ water during menstruation was significantly higher $(\mathrm{p}<0.05)$ than the baseline value. Similarly the two hour post ingestion of same concentration was significantly higher $(\mathrm{p}<0.05)$ than the baseline value. 


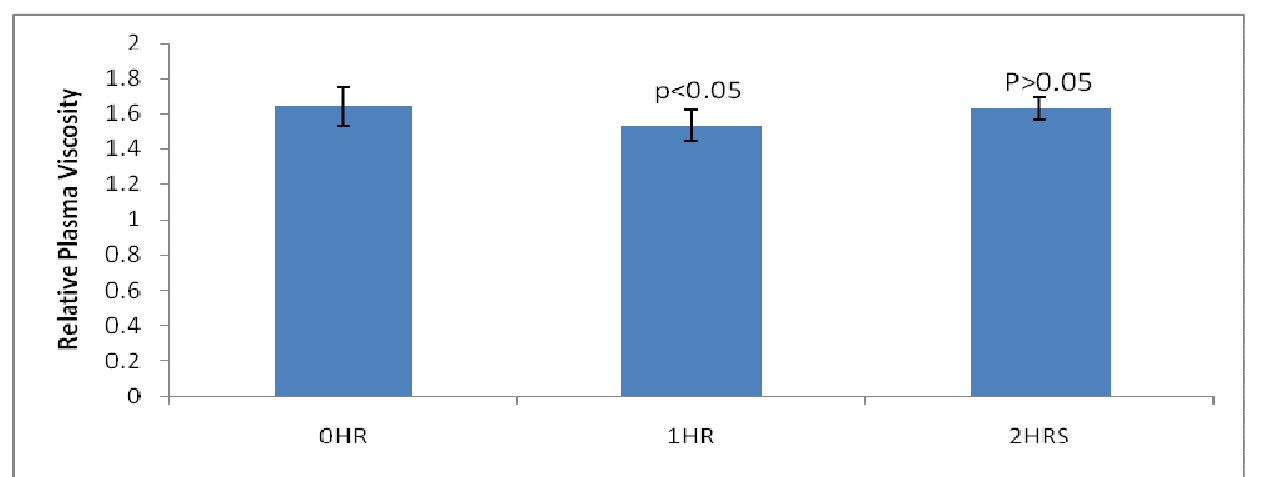

Figure 2: Relative plasma viscosity at $1 \mathrm{hr}$ and $2 \mathrm{hrs}$ after ingestion of $39 \mathrm{~g}$ of glucose $/ 200 \mathrm{mls}$. The Relative Plasma Viscosity after $1 \mathrm{hr}$ of ingestion of $39 \mathrm{~g}$ glucose $/ 200 \mathrm{mls}$ water during menstruation was significantly higher $(\mathrm{p}<0.05)$ than the baseline. However, the two hour post ingestion value was not statistically different $(\mathrm{p}>0.05)$ from the baseline.

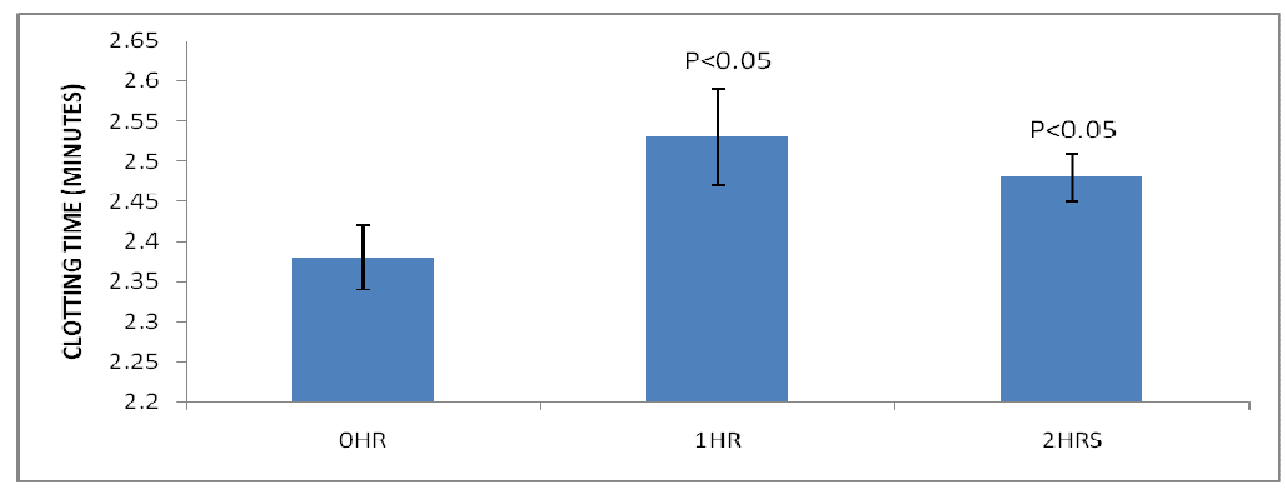

Figure 3: Clotting time at $1 \mathrm{hr}$ and $2 \mathrm{hrs}$ after ingestion of $78 \mathrm{~g}$ of glucose $/ 200 \mathrm{mls} \mathrm{H}_{2} \mathrm{O}$. The clotting time followed the same pattern as that of ingestion $39 \mathrm{~g}$ glucose $/ 200 \mathrm{mls}$ of water, despite the higher concentration of $78 \mathrm{~g}$ glucose $/ 200 \mathrm{mls}$ of water.

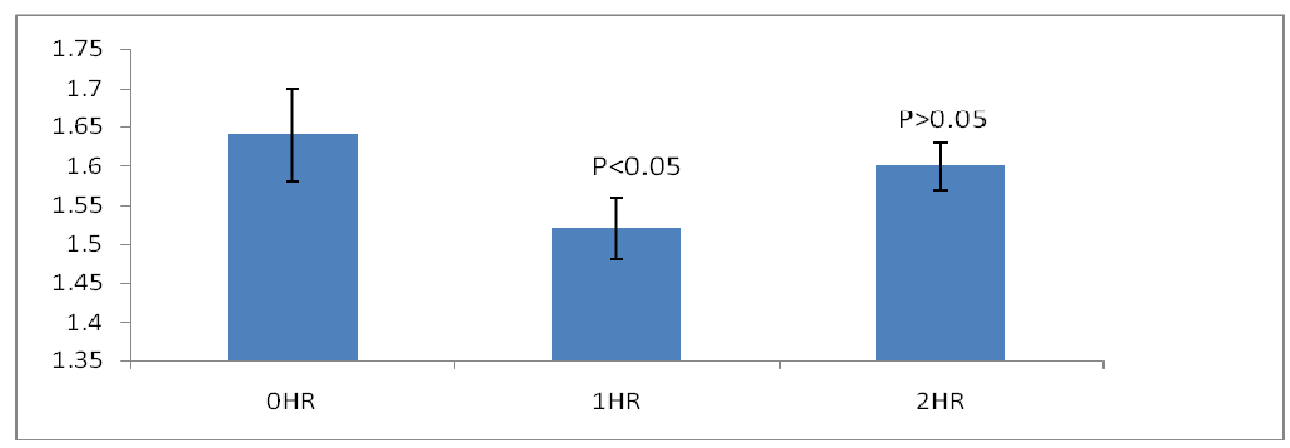

Figure 4: Relative Plasma Viscosity at $1 \mathrm{hr}$ and $2 \mathrm{hrs}$ after ingesting $78 \mathrm{~g}$ glucose $/ 200 \mathrm{mls}_{2} \mathrm{O}$. The same pattern for RPV following ingestion of a lower concentration of glucose was observed i.e. the Relative Plasma Viscosity after $1 \mathrm{hr}$ of ingestion of $78 \mathrm{~g}$ glucose $/ 200 \mathrm{mls}$ water during menstruation was significantly higher $(\mathrm{p}<0.05)$ than the baseline. However, the two hour post ingestion value was not statistically different $(p>0.05)$ from the baseline values. 


\section{DISCUSSION}

The menstrual cycle is characteristically divided into four phases with each phase having associated hematologic changes (Omorogiuwa and Egbeluya, 2014). The phases are menstrual follicular, ovulation and luteal. The menstruation phase, which is the most obvious phase of the cycle, has been observed to be affected by sugar intake. However, most studies on the effect of sugar on coagulation factors have been on diabetic subjects. For instance, Sambola et al. (2003) reported that a circulating pool of tissue factor in blood associated with cells and microparticles is thrombogenic and is elevated in type 2 diabetes.

In menstruating girls there is evidence suggesting that there is reduction in platelet count which explains the increase in bleeding time and clotting time (Rajnee et al., 2010). Clotting time which is the time taken for blood to clot after an injury is a function of both platelets and plasma proteins. Plasma is a highly concentrated protein solution and its viscosity is determined basically by water content and macromolecular component of blood (Gabor et al., 2008). Among the plasma proteins, fibrinogen is the major determinant of plasma viscosity (Erdal et al., 2010). Results from this study showed a significant increase in clotting time during menstruation in accordance with a previous work done on this subject (Rajnee et al., 2010). The rise in clotting time in addition to the decrease in relative plasma viscosity from the ingestion of glucose may have increased the menstrual blood flow. Furthermore, acute hyperglycemia increases muscle blood flow and alters endothelia function in adolescents with type 1 diabetes (Amanda et al., 2012).

Menstrual endometrial breakdown induced by estradiol and progesterone withdrawal is regularly attributed to a sequence of vasospasm of the endometrial spiral arteries (Pauline et al., 2013), vasodilation in these vessels, increased blood flow and increased fibrinolytic activity. Although studies have shown that hyperglycemia in daibetics increases plasma fibrinogen levels, relativeplasma viscosity, blood viscosity and coagulability (Carr, 2001; Edem et al., 2010; Lemkes et al., 2010), the increase fibrinolytic activity of menstruation may have countered the hypercoagualable state of the induced acute hyperglycemia, consequently, reducing plasma viscosity and increasing clotting time (Figures1, 2, 3, 4). The increase in clotting time during menstruation is as a result of the reduced platelet count (Rajnee et al., 2010). Nevertheless, the view on the effect of blood sugar on clotting time is divergent as Moreno et al. (2000) and Vijender (2006) revealed that sugar decreases the clotting time in the body.

\section{Conclusion}

From this study, the reduction in plasma viscosity increased clotting time and the increased endothelial blood flow following acute hyperglycemia may explain the increased menstrual flow experienced by the subjects. Since findings from this research suggest that glucose intake can lead to increase in clotting time and decrease in relative plasma viscosity with a perceived increased in menstrual blood flow, we recommend that females should reduce glucose intake during menstruation.

\section{REFERENCES}

Amanda SD, Hong H, John AB, Robert PH. 2012. Hyperglycemia Increases Muscle Blood Flow and Alters Endothelial Function in Adolescents with Type 1 Diabetes. Experimental Diabetes Research; Article ID 170380, 9 pages http://dx.doi.org/10.1155/ 2012/170380

Carr ME. 2001. Diabetes mellitus: a hypercoagulable state. Journal of Diabetes and its Complications, 15(1): 44-54.

Dapper DVB, Didia BC. 2002. Hemorrheological Changes During the Menstrual Cycle. East African Medical Journal, 79: 181-183.

Edem MS, Emeribe AO, Akpotuzor C. 2009. Changes in haemorrheological and fibrinolytic activities upon hypertension and diabetic chemotherapy in Calabar 
diabetic residents, Nigeria Academic Journals, 4: 28-32.

Erdal K, Emin A, Tarik ZN, Swvsen K, Gokhan M. 2010. Value of plasma viscosity in acute appendicitis: a preliminary study. Journal of Medicine and Medical Sciences, 1: 423-425.

Franca C, Giulio G, Renzo C. 2000. Serum leptin concentrations during the menstrual cycle in normal-weight women: effects of an oral triphasic estrogen-progestin medication. European Journal of Endocrinology., 142: 174178.

Furie B, Furie B. 2005. Thrombus formation in vivo. Journal of Clinical Investigations, 115: 3355-3362.

Gabor K, Peter K, Miklos R, Kalman T. 2008. Plasma viscosity: A forgotten variable. Clinical Hemorrheology and microcirculation., 39: 243-246. Doi 10.3233/CH-2008-1088.

Guyton AC, Hall JE. 2006. Textbook of Medical Physiology. $11^{\text {th }}$ ed. Saunders Philadephia, pp 419-429.

Kim EB, Scott B, Susan MB, Heddwen LB. 2010. Ganong's Review of Medical Physiology $\left(23^{\text {rd }}\right.$ edn). Tata McGraw Hill Education Private Limited: New Delhi.

Lemkes BA, Hermanides J, Devries JH, Holleman F, Meijers JC, Hoekstra JB. 2010. Hyperglycemia: a prothrombotic factor J. Thromb Haemost, 8(8):16631669.

Liu Y, Gold BE, Lesley LB, Johnson OW. 2004. Factors Affecting Menstrual Cycle Characteristics. American Journal of Epidemiology, 160: 131-140.

Loucks AB, Redman LM. 2004. The effect of stress on menstrual function. Trends Endocrinol Metab., 15(10): 466-471.

Moreno PR, Murcia AM, Palacios IF, Leon MN, Bernardi VH, Fuster V, Fallon JT. 2000. Coronary Composition and Macrophage Infiltration in Atherectomy
Specimens from Patients with Diabetes Mellitus. Circulation, 102: 2180-2184.

Olatunji LA, Soladoye AO, Ighoroje ADA, Attah AO. 2008. Influence of hyperglycemia on hemorrheological markers in diabetic Nigerians. Journal of Medicine and Biomedical Research., 7:51-57.

Omorogiuwa A, Egbeluya EE. 2014. A Comparative Study of the Hematological values in the Ovulation and Luteal phases of the Menstrual cycle. Int. J. Biol. Chem. Sci., 8(4): 1853-1858.

Pauline C, Pascale L, Benedicte FJ., et al. 2013. Hypoxia is not required for human endometrial breakdown or repair in a xenograft model of menstruation. The Faseb Journal., 27: 1-9.

Rajnee VKC, Raghuveer C, Bijendra KB, Sunita C. 2010. Hematological and electrocardiographic variations during menstrual cycle. Pakistan Journal of Physiology, 6:18-21

Reid HC, Ugwu CA. 1987. A simple technique for rapid determination of plasma viscosity. Nig $J$ Physiological Sci., 3: 45-48.

Sambola A, Osende J, Hathcock J, et al. 2003. Role of risk factors in the modulation of tissue factor activity and blood thrombogenicity. Circulation, 107: 973977

Vijender RV, Koneti AR, Maria M, Carol H, Peter C, Guenther B. 2006. Effects of hyperglycemia and hyperinsulinemia on circulating tissue factor procoagulant activity and platelet CD40 ligand. Diabetes Journal, 1: 202-208. 